\title{
Use of Compton Back Scattering Technique for Detection of Corrosion in Pipes
}

\author{
Iman Tarik Al-Alawy ${ }^{a, *}$ Alaa B. Kadhim ${ }^{b}$ Sura Salim Ahmed ${ }^{c}$ \\ ${ }^{a}$ Al-Mustansiriyah University, College of Science, Physics department, Baghdad - Iraq \\ ${ }^{\mathrm{b}}$ Baghdad University, College of Science, Physics department, Baghdad - Iraq \\ ${ }^{\mathrm{c}}$ Technology University, Materials Engineering, Baghdad - Iraq \\ *Email: drimantarik@yahoo.com
}

Keywords: Compton backscattering; corrosion detection; gamma - ray interaction; nondestructive technique; pipes.

\begin{abstract}
The multiple Compton backscattering (MCBS) technique has been used to investigate the detection and imaging corrosion under the insulation pipe. An energy source with a mono - energy $0.662 \mathrm{MeV}$ of ${ }^{137} \mathrm{Cs}$ has been used. Gamma ray photons have been allowed to be incident vertically on the insulator pipe whose outside diameter, wall and asbestos insulation thickness are $(28,1,4) \mathrm{cm}$ respectively. The steel pipe has a corrosion defect with a diameter $8 \mathrm{~cm}$. The count rate of scattered $\gamma$ - photons with scattering angle in the range $(130-140)$ degrees has been collected by $\mathrm{NaI}(\mathrm{Tl})$ detector with different radius. Assuming the source and detector locations are in the same side from the pipe. Monte Carlo simulation has been written in FORTRAN95 language programming to follow the history of photons. This study provides the ability of this technique to detect and imaging the corrosion under the insulator pipes. The radius of detector which gives good results for corrosion detection and imaging is $6 \mathrm{~cm}$ among five different selected radiuses.
\end{abstract}

\section{INTRODUCTION}

Piping is a common feature in industries. It provides the most economical, safe and efficient way of transporting chemicals in the form of liquids and gases from point to another. As a result, a large amount of piping construction has been carried out in the world. A considerable proportion of piping is used in power stations, petroleum and chemical plants in transporting water, steam, petroleum and chemical products at moderate or high temperatures. This piping is usually covered by thick insulation materials, such as asbestos, nylon cloth, concrete or lime. Because pipe experiences degradation with time due to the transported media usually has high pressure, poisonous and combustible characteristics, which if not detected might create problems such as leaks or explosion will finally cause pollution, casualties and immense economic loss. Corrosion, erosion, deposits and pipe blockage are some of the possible causes for this $[1,2]$. As a result, a nondestructive testing (NDT) technique which can conveniently be used in the field, and which can quantitatively express the corrosion status of steel structures under insulation, would be highly desirable [3]. The (NDT) technique investigated in present work is gamma backscattering method for detecting corrosion in the pipeline, because it has the following features attractive for on - site structural crack detection: (1) It is a nondestructive and non - contact method; (2) It can detect a crack below the surface; (3) It is not susceptible to surface roughness and material properties, except their densities; and (4) The source and detector can be located on the same side of the object, enabling testing of massive extended structures [4]. Asa'd (1997) [5] measuring the wall thickness of steel sections also by Compton backscattering. Khiem and Khai (2000) [6] developed a Monte Calro simulation to describe the interaction processes of gamma rays when coming in a medium and register the backscattered events are used to reproduce the shape of defects existing in the testing material, whereas Sheng (2002) [7] used the same method to detect the buried landmines. Naito and Yamamoto (2009) [4], successfully detected crack below deposit by using X - ray backscattering technique. Abdul - Majid and Tayyeb (2005) [8] and Abdul - Majid and Balamesh 
(2012) [9] used gamma ray backscattering method for inspection and imaging corrosion under insulation. Grubsky and et al. (2013), describe Compton imaging tomography (CT) for reconstructing complete three - dimensional (3D) internal structure of an object, based on acquiring multiple Compton scattered $\mathrm{X}$ - ray images of object cross sections, and find the benefits of the backscatter $\mathrm{X}$ - ray from one - side operation, provides true high resolution $3 \mathrm{D}$ topographic data and allows inspecting deep layers of a structure [10]. The aim of this work is to detect and image the corrosion under insulating pipes in nondestructive inspection through using multiple Compton back scattering technique. The principle of this method depended on the Compton scattering for multiple scatter of $\gamma$ photons through examine an algorithms dependent on the mass absorption coefficients and the area of corrode and non - corrode region of the pipe materials by Fortran Monte Carlo simulation.

\section{THE GEOMETRY TECHNIQUE}

The principle of (MCBS) technique assuming the scattering region has been confined to plane, then for a point source and detector, suggests that any scattered energy (É) corresponds to a precise angle $\left(\theta_{\text {Comp }}\right)$ that define a circular "isogonic" arc of possible scattering locations. Measuring over much energy at several detector locations produces an intersecting mesh of isogonic arcs as shown in Fig. 1 (a) [11]. The functioning principle of Compton scattering imaging and the shielding of the source prevents photons reaching the detector directly is given by Fig. 1 (b) [12].

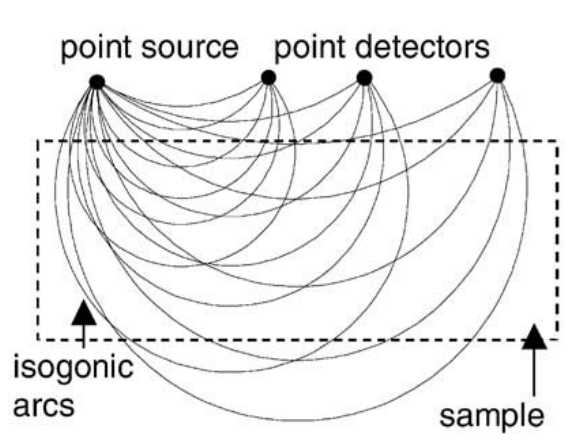

(a)

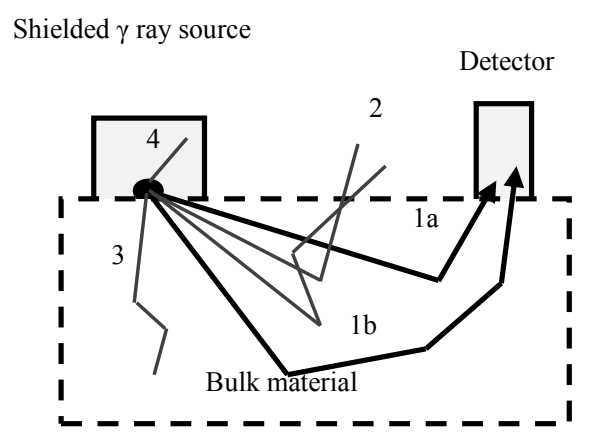

(b)

Fig. 1: (a) Mesh of isogonic arcs defined by point source and detectors [11]. (b) Single and multiple gamma backscattering principle, where photons emitted from the source are either: 1; detected having undergone single 1a or multiple $1 \mathrm{~b}$ scattering in the material. 2 ; lost though the surface by single or multiple scattering in the material. 3 ; lost by scattering and absorption in the material, or 4; stopped by the source shielding [12].

Fig. 2 illustrates an iron pipe used in the present work with $140 \mathrm{~cm}$ long, $28 \mathrm{~cm}$ outside diameter (26 cm inside diameter) and $1 \mathrm{~cm}$ wall thickness, with defect on its inside surface has a shape close to a circular with corrosion diameter (CD) of about $8 \mathrm{~cm}$. The pipe has asbestos insulator of $4 \mathrm{~cm}$ thickness, which is neglected in the calculation due to its low atomic number and density material. Moreover, the backscattered radiation from the insulator is almost constant along the pipe; corrosion takes place in the pipe wall. Hence, it will cause no significant interference. The geometry of (MCBS) technique employed in this work is illustrated in Fig. 3. Where, a point source of gamma ray locates at a distance $8 \mathrm{~cm}$ from the pipe surface. The gamma photons which is incident perpendicular on the pipe surface, suffer scattering or multiple scattering after interaction with the pipe material. 


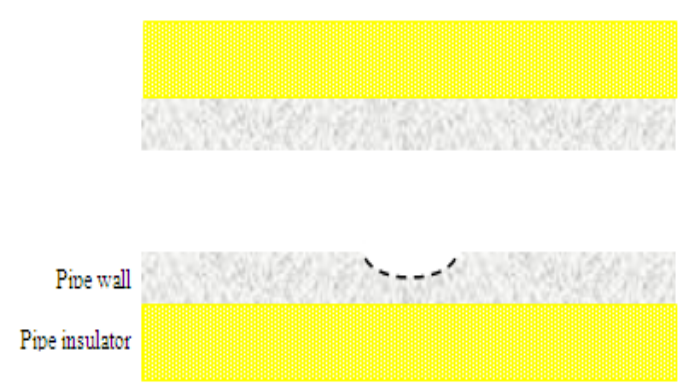

Fig. 2: The specimen pipe.

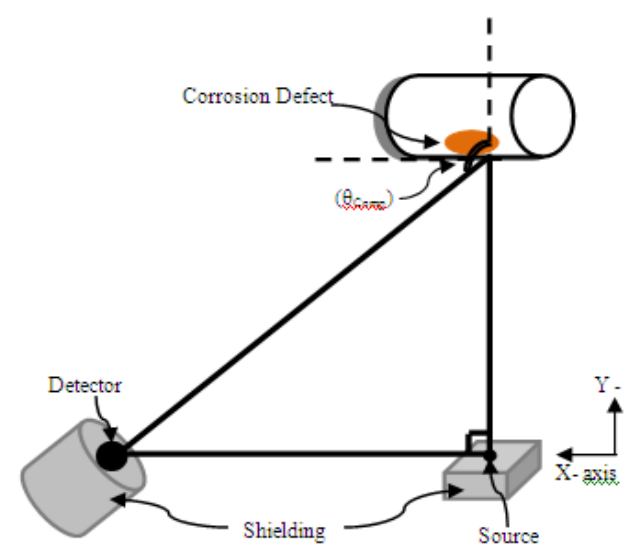

Fig. 3: The Geometry Technique.

The Compton scatter angle $\left(\theta_{\text {Comp }}\right)$, which studying in this work, is in the range130-140 degree with average angle 135degree. Therefore, the scattered photons will be detected by the detector separated by $7 \mathrm{~cm}$ far from the source. The point source of $\gamma-$ ray selected is ${ }^{137} \mathrm{Cs}$ with mono - energy $0.662 \mathrm{MeV}$. The $\mathrm{NaI}(\mathrm{Tl})$ scintillation gamma detector has been used with different radius $\mathrm{RD}=3,4,5,6$ and $7 \mathrm{~cm}$. Each of source and detector have been shielding by using lead $(\mathrm{Pb})$ to prevent registering the photons that come directly from the source without passing in the material, also both of them located on the same side from the pipe surface.

\section{THE ALGORITHM OF MONTE CARLO SIMULATION}

The algorithm of this work has a main program for the data preparation and interpolation, which has two main subroutines for non - corrosion (iron Fe area) and corrosion (iron oxide $\mathrm{Fe}_{2} \mathrm{O}_{3}$ area).The histories of a large number of photons emitted from the source are followed by using Monte Carlo simulation through Fortran95 language to determine the distribution of the backscatter radiation. A random number $(v)$ is used to obtain a uniform distribution within the range $(0 \leq v \leq 1)$. Simulation of a photons history requires the following procedure:

1) Supposing the pipe material consists of $\mathrm{Fe}$ and $\mathrm{Fe}_{2} \mathrm{O}_{3}$ to simplify the simulation required.

2) The area divides into 70 sectors along the pipe and 25 sectors over the width with an increment of $0.2 \mathrm{~cm}$ respectively. The corrosion area had been calculated implicit with sectors from 16 to 55 in length and from zero to 20 sectors in width, as illustrate in Fig. 4. Hence these data could be fed into the initiated program otherwise to detect the corrosion area.

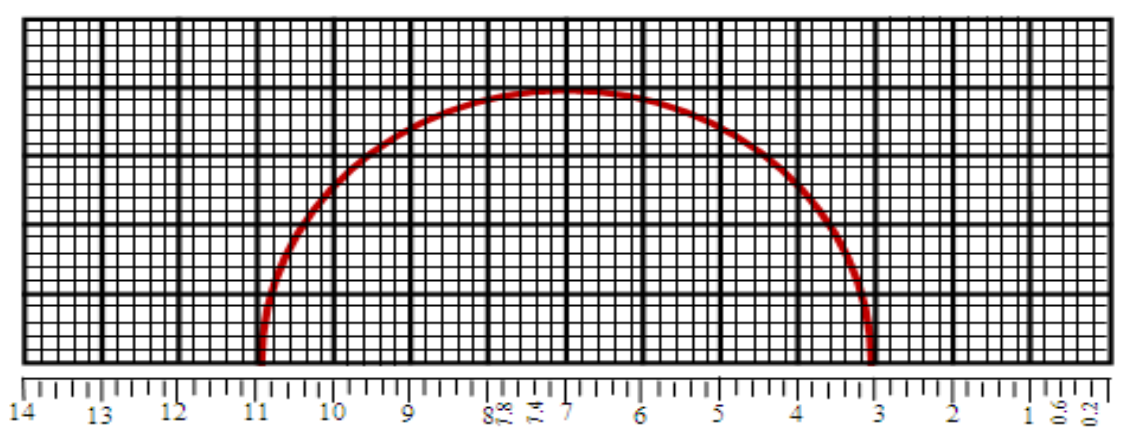

Fig. 4: Block diagram of pipe area. 
3) The values of mass attenuation coefficients $(\mu)$ related to the energy range from $1 \mathrm{keV}$ to $1 \mathrm{MeV}$, has been collected from XCOM [13], for iron and iron oxide, respectively. The collected data had been used in the initiated to develop the interpolation function.

4) In polar coordinate, a photon with incident gamma energy $\left(E_{0}\right)$ is emitted randomly as a function of polar angle $\left(\theta_{\mathrm{Ph}}\right)$ and azimuthal angle $\left(\varphi_{\mathrm{Ph}}\right)$. Cosine - sampling has been used for the polar angle $\theta_{\mathrm{Ph}}$ and uniform sampling for the azimuthal angle $\varphi_{\mathrm{Ph}}[14]$ :

$$
\begin{aligned}
& \theta_{\mathrm{Ph}}=\cos ^{-1}\left(2 v_{1}-1\right) \\
& \varphi_{\mathrm{Ph}}=\pi v_{2}
\end{aligned}
$$

5) The energy of scattered photon is obtained using Khan Method [14]. This method is used for random numbers sampling as shown in Fig. 5.

6) The polar angle $\left(\theta_{\text {Comp }}\right)$ of scattered photon is given by Compton formula $[14,15]$ :

$$
\cos \theta_{\text {Comp }}=1-\left(\frac{1}{\hat{E}}-\frac{1}{E_{0}}\right) m_{0} c^{2}
$$

Where $\mathrm{E}_{\mathrm{O}}$ and É are old and new energies and $\mathrm{m}_{\mathrm{O}} \mathrm{c}^{2}=0.511 \mathrm{MeV}$.

7) Sampling for the actual path length (PL) of the photon in the material, is given by [14]:

$\mathrm{PL}=-\frac{1}{\mu(\mathrm{E})} \ln \left(1-v_{8}\right)$

8) For multiple scattering of photons the program which has been installed in this work could be transform to different subroutines for determine the new scattering angles $(\alpha, \beta, \gamma)$ through the initial unit vector (n).

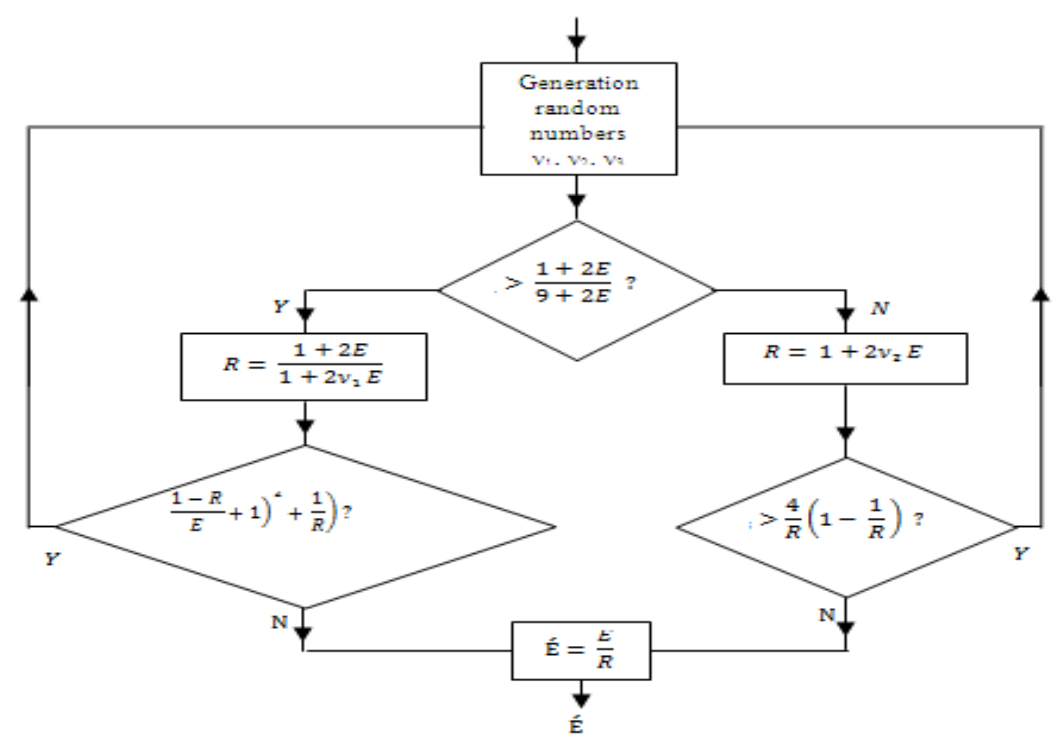

Fig. 5: Kahn method used for random sampling of the Klein-Nishina distribution. $v_{\mathrm{i}}$ are random numbers uniformly distributed in the range $0 \leq v_{\mathrm{i}}<1, \mathrm{E}$ and $\mathrm{E}$ are the initial and final proton energies (in units of the electron rest mass energy), and $\mathrm{R}$ is the retio E/É [14]

\section{RESULTS AND DISCUSSION}

For detecting and imaging the corrosion in the pipe, the pipe area should be divided into many sectors for source and detector in $\mathrm{x}, \mathrm{y}$ plane, that could be scanning the whole area of the pipe. The scanning increment is $0.2 \mathrm{~cm}$ for each scanner movement. The photon history from its project point until detect or register by detector is simulated by this procedure. Notice that the count rate of back scatter photons will be decrease when scanning is in the location posses a corrosion. So, after complete scanning area of the pipe, the image had been got in two dimensions (2D) of the corrosion. This is illustrated in fig. 6-a, b, c, d and e that show images in 2D of circular corrosion $\mathrm{Fe}_{2} \mathrm{O}_{3}$ in the steel $\mathrm{Fe}$ wall pipe for different radius of detector. On these figures, the black colors indicate to back scattering photons from Fe location and red colors are for $\mathrm{Fe}_{2} \mathrm{O}_{3}$ location. Also, 
these figures show the count rate of register back scatter photons which increase gradually when increasing the radius of detector from $3 \mathrm{~cm}$ until $5 \mathrm{~cm}$, as seen in Fig. $6-\mathrm{a}, \mathrm{b}$, and $\mathrm{c}$, whereas, the count rate will be constant from radius $5 \mathrm{~cm}$ to $7 \mathrm{~cm}$, as seen in Fig. $6-\mathrm{c}$, d, and e, i.e., excellent detection and complete image can be obtained when the radius of the detector is $5 \mathrm{~cm}$ or greater. The lacks in the count rate of back scatter photons is obviously clear when using a detector with radius less than $5 \mathrm{~cm}$ due to the statistical counts in the procedure of simulation used in this work. For more illustration, summaries of the count rate data of back scattered photons are tabulated in table 1 , which shows that the total number of back scattered photons at a selected Compton angle $\left(\theta_{\text {comp }}\right)$ and the total number of scattered photons that detects or registers through a detector at different radius for both $\mathrm{Fe}$ and $\mathrm{Fe}_{2} \mathrm{O}_{3}$. Fig. 7-a, b, c, d and e shows the count rate behavior of backscattered photons in all sectors with $0.2 \mathrm{~cm}$ increment for radius detector $\mathrm{RD}=3,4,5,6$ and 7 for $\mathrm{Fe}$ and $\mathrm{Fe}_{2} \mathrm{O}_{3}$ respectively. Therefore, when photons scanning the pure area Fe of the pipe surface, the count rate will be increased, while it decreases when scanning arrived to the corrosion area $\mathrm{Fe}_{2} \mathrm{O}_{3}$; whereas when photons scanning the corroded area $\mathrm{Fe}_{2} \mathrm{O}_{3}$ the count rate will be increased because the amount of $\mathrm{Fe}$ will decrease in comparison with $\mathrm{Fe}_{2} \mathrm{O}_{3}$ in the pipe surface, in addition to the affected of count rate by the attenuation coefficient of photons. Since the attenuation coefficient depends on the density of elements, i.e. if the material has a high density, the attenuation coefficient has small value, thus the count rate of scattered photon will be decrease, and vice versa. On this figures, red color points and line is the count rate behavior for a pure area $\mathrm{Fe}$ and blue color points and line is for corrosion are $\mathrm{Fe}_{2} \mathrm{O}_{3}$.

\section{CONCLUSIONS}

The results described clearly that (MCBS) technique simulation by gamma ray is very powerful technique for detecting and imaging the corrosion of steel pipes with or without insulator. Comparing with the most commonly used methods for the detection of corrosion, this technique can be used without any damage being caused to the inspection pipe. This makes it possible to follow the detection and imaging corrosion during the pipe. The summarized results are as follows:

- The ratio of count rate for back scatter photons increase with increasing the detector radius from radius $3 \mathrm{~cm}$ to $5 \mathrm{~cm}$, while it is fixed for radius $5 \mathrm{~cm}$ and greater.

- Generally, in the corrosion area the count rate for Fe is reduced compared to the non-corrosion area, while $\mathrm{Fe} 2 \mathrm{O} 3$ count rate is increased in corrosion area.

- Choose detector with radius $6 \mathrm{~cm}$ the best radius because it is a minimum radius that could use to give complete and excellent results.

- The reduction in the Fe count rate is about $33.3 \%$ of that for non-corrosion area when using detector with radius $\mathrm{RD}=6 \mathrm{~cm}$.
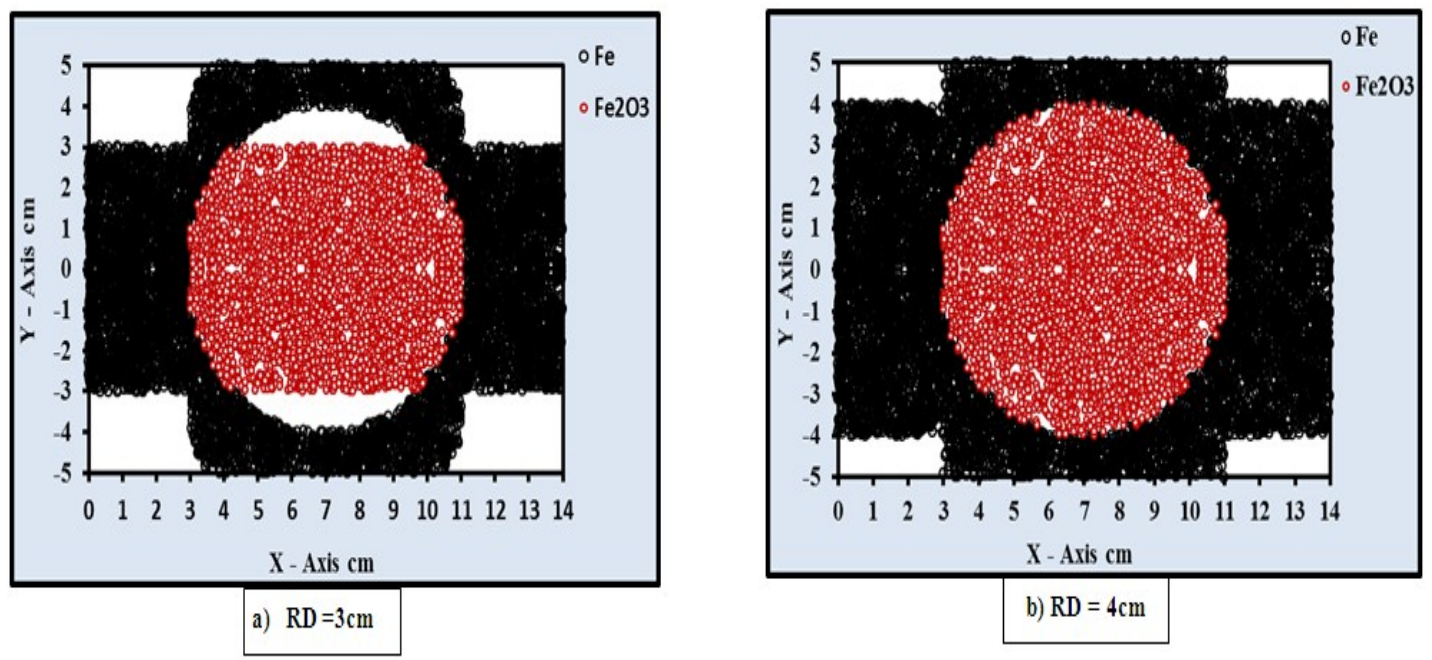

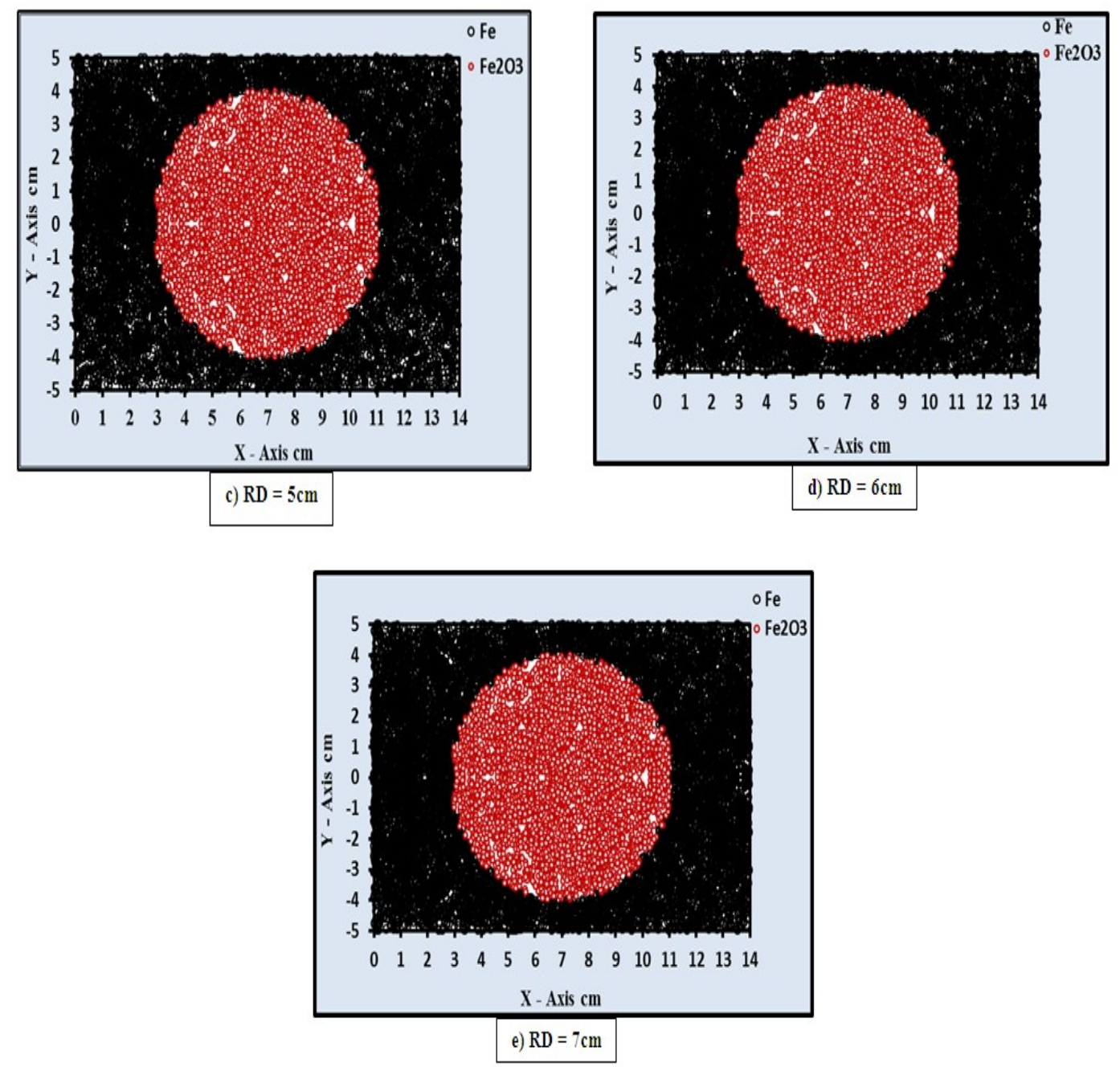

Fig. 6: The 2D imaging simulation results for (MCBS) technique with different radii of detector; a) $\mathrm{RD}=3 \mathrm{~cm}, \mathrm{~b}) \mathrm{RD}=4 \mathrm{~cm}, \mathrm{c}) \mathrm{RD}=$ $5 \mathrm{~cm}$,

Table 1 Scattered and detected photons at different radius detector for Fe and $\mathrm{Fe}_{2} \mathrm{O}_{3}$ at $\theta_{\text {Comp }}$ average.

\begin{tabular}{|c|c|c|c|c|c|c|}
\hline \multirow{2}{*}{$\begin{array}{c}\text { Detector } \\
\text { radius cm }\end{array}$} & \multicolumn{2}{|c|}{$\begin{array}{c}\text { Scattered } \\
\text { photons }\end{array}$} & \multicolumn{2}{c|}{$\begin{array}{c}\text { Detected } \\
\text { photons }\end{array}$} & \multicolumn{2}{c|}{$\begin{array}{c}\Theta_{\text {Comp }} \text { averge } \\
\text { (min - max) degree }\end{array}$} \\
\cline { 2 - 7 } & $\mathrm{Fe}$ & $\mathrm{Fe}_{2} \mathrm{O}_{3}$ & $\mathrm{Fe}$ & $\mathrm{Fe}_{2} \mathrm{O}_{3}$ & $\mathrm{Fe}$ & $\mathrm{Fe}_{2} \mathrm{O}_{3}$ \\
\hline 3 & 473706 & 255831 & 3485 & 1543 & $133.28-135.59$ & $133.75-135.66$ \\
\hline 4 & 474545 & 257089 & 4107 & 1750 & $133.28-135.59$ & $133.91-135.66$ \\
\hline 5 & 474547 & 259746 & 4567 & 1766 & $133.28-135.59$ & $133.91-135.66$ \\
\hline 6 & 474547 & 259746 & 4567 & 1766 & $133.28-135.59$ & $133.91-135.66$ \\
\hline 7 & 474547 & 259746 & 4567 & 1766 & $133.28-135.59$ & $133.91-135.66$ \\
\hline
\end{tabular}

Note: Supposed the total number of incident photons 20000 photon 

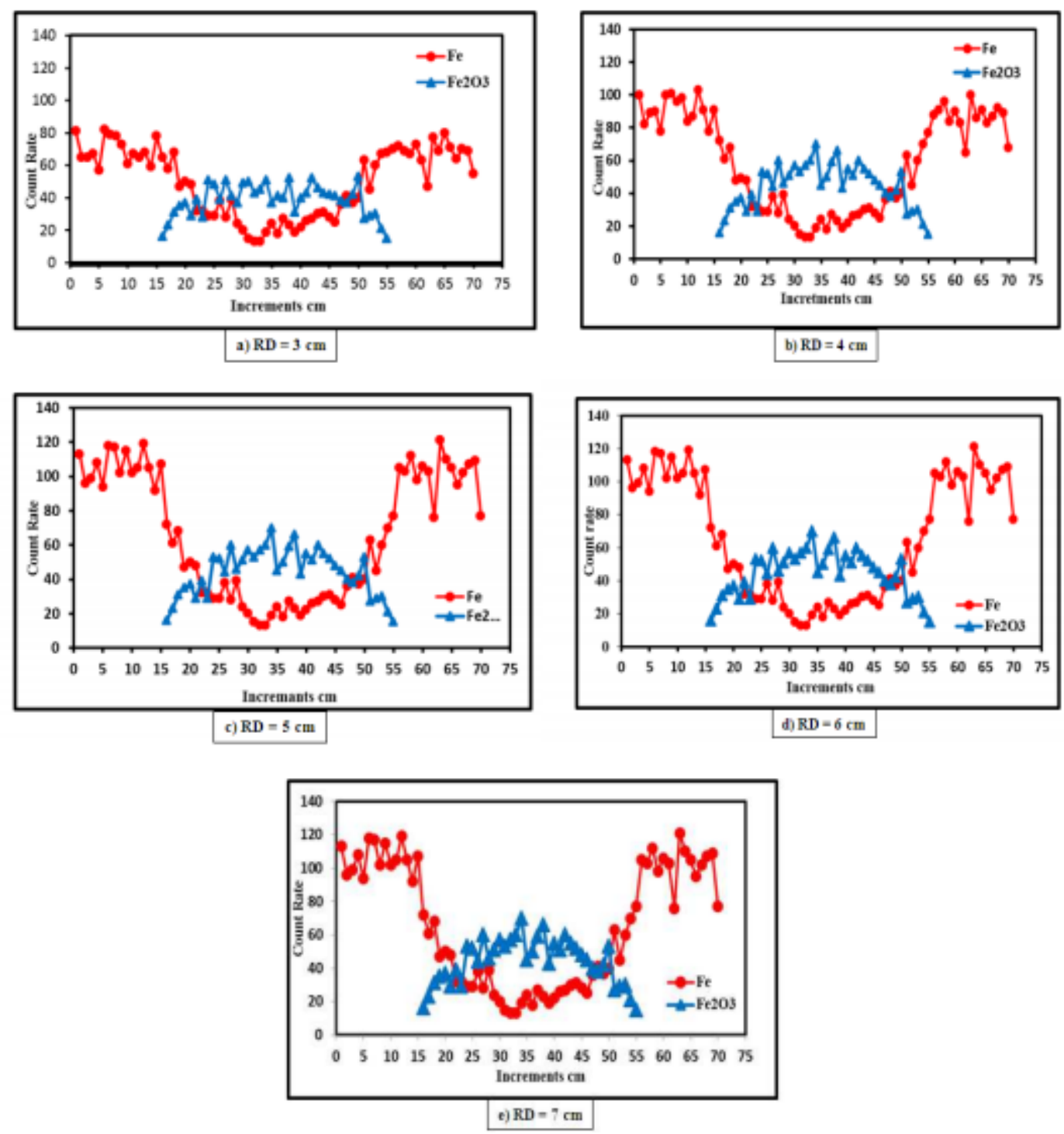

Fig. 7: The count rate behavior of scattered photons from (MCBS) technique simulation for different detector radius: a) $\mathrm{RD}=3 \mathrm{~cm}$, b) $\mathrm{RD}=4 \mathrm{~cm}, \mathrm{c}) \mathrm{RD}=5 \mathrm{~cm}, \mathrm{~d}) \mathrm{RD}=6 \mathrm{~cm}, \mathrm{e}) \mathrm{RD}=7 \mathrm{~cm}$.

\section{Acknowledgments}

The authors thank the Dean of the College of Science and the Head of Department of Physics at AlMustansiriyah University for supporting this research.

\section{References}

[1] J. Zirnhelt, I. Einav and S. Infanzón,"Radiographic evaluation of corrosion and deposits: An IAEA Co-ordinate Research Project", 3rd PAN American Conference for NonDestructive Testing- PANNDT. 02 to 06 June, Rio de Janeiro, RJ, Brazil, (2003).

[2] IAEA - TECDOC - 1445, "Development of protocols for corrosion and deposits evaluation in pipes by radiography", International Atomic Energy Agency (IAEA), April, (2005).

[3] P.S. Ong, V. Patel and A. Balasubramanyan,"Quantitative characterization of corrosion under insulation", Journal of Nondestructive Evaluation, 16(3) (1997) 135-146.

[4] S. Naito and S. Yamamoto, "Novel X-ray backscatter technique for detecting crack below deposit", Toshiba Corporation, Japan. http://www.ndt.net/article/jrc-nde2009/papers/110.pdf. 
[5] Z. Asa'd, M. Asghar, and D. C. Imrie, "The measurement of the wall thickness of steel sections using Compton backscattering", Meas. Sci. Technol., 8(4) (1997) 377. doi:10.1088/09570233/8/4/003.

[6] Khiem, Le Hong and Khai, Nguyen Tuan, "Monte - Carlo simulation for reproducing image of an object using Compton back scattering", Proceedings of the $15^{\text {th }}$ World Conference Non Destructive Testing (WCNDT), Romma, (2000).

[7] Sheng. Tang Shuo, "Detection of buried landmines by Compton backscattering", M.Sc.Thesis in Mechanical Engineering, University of New Brunswick, Fredericton, Canada, September, (2002).

[8] S. Abdul-Majid and Z. Tayyeb, "Use of gamma ray backscattering methods for inspection of corrosion under insulation". $3^{\text {rd }}$ MENDT-Middle East Nondestractive Testing Conference and Exhibition-27-30 Nov., Bahrain, Manama, (2005). www.ndt.net

[9] S. Abdul-Majid and A. Balamesh," Imaging corrosion under insulation by gamma ray backscattering method". 18 ${ }^{\text {th }}$ World Conference Nondestructive Testing, 16-20 April, Durban, South Africa, (2012) 1-7.

[10] V. Grubsky, V. Romanov, E. Patton and T. Jannson,"Compton imaging tomography for 3D inspection of complex structurs and real - time process control". ASNT 22nd Research Symposium, 18-21March. The American Society for Nondestructive Testing, Inc. (ASNT). ASNT ResearchCouncil.,(2013).

https://www.asnt.org/ /media/.../Spring\%202013\%20brochure.ashx

[11] B.L. Evans, J.B. Martin, L. Burggraf, M.C. Roggemmann and T.N. Hangartner, "Demostration of energy - coded Compton scatter tomography with fan beams for one - sided inspection", Nuclear Instruments and Methods in Physics Research A, 480, (2002) 797-806.

[12] A.J. Ball, C. J. Solomon and J.C. Zarnecki, "The response of gamma backscatter density gauges to spatial inhomogensity-an extension of the single scattering model", Nuclear Instruments and Methods in Physics Research B, 140 (1998) 449-462.

[13] J.H. Hubbell and S.M. Seltzer, "Tables of $\mathrm{x}$ - ray mass attenuation coefficients and mass energy-absorption coefficients from $1 \mathrm{keV}$ to $20 \mathrm{MeV}$ for elements $\mathrm{Z}=1$ to 92 and 48 additional substances of dosimetric interest", (NIST) National Institute of Standard and Technology, Physical Measurement Laboratory, XCOM Photon Cross - Sections Database., (1996). http://www.nist.gov/pml/data/xraycoef/index.cfm/

[14] A.J. Ball,"Measuring physical properties at the surface of a comet nucleus". Ph.D. Thesis. Units for Space Science and Astrophysics, University of Kent, Canterbury, UK, (1997). https://kar.kent.ac.uk/id/eprint/23088

[15] R.D. Evans, "The Atomic Nucleus, The interaction of electromagnetic radiation with matter: compton scattering and absorption", McGraw-Hill, Inc., (1955) 672-693. 